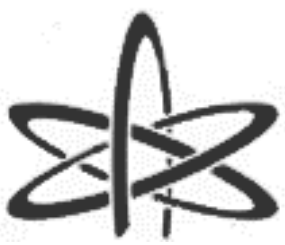

BJRS
BRAZILIAN JOURNAL

OF

RADIATION SCIENCES

09-02 (2021) 01-19

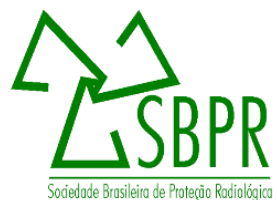

\title{
Dose distribution in a radiosurgery treatment for an acoustic neuroma
}

\author{
Cardoso $^{a}$ M.A.C., Alves ${ }^{\mathrm{a}}$, V.G.L., Cardoso ${ }^{\mathrm{a}}$ S.C. \\ ${ }^{a}$ Instituto de Física/UFRJ, 21943-972, Rio de Janeiro, Rio de Janeiro State, Brazil \\ e-mail_address_of_the_corresponding_simone@if.ufrj.br
}

\begin{abstract}
Evaluation of the dose distribution delivered in a radiosurgery treatment of an acoustic neuroma using an adapted Alderson phantom and radiochromic film to assess absolute dose. A system was developed to perform the dose measurements, using the Alderson Rando phantom's head carrying a modified slice, where objects reproducing the tumor and brainstem were inserted. The phantom's head with the modified slice was irradiated in a medical linear accelerator. Radiochromic films were used to assess dose values. The suitability of the dose distribution delivered in the treatment was evaluated by comparing the Dose Volume Histograms, obtained from the Treatment Planning System (TPS) and by radiochromic film measurements. An agreement around 3\% between experimental data and TPS's calculations for the tumor was found, showing an acceptable concordance with the planning results. For brainstem, TPS underestimated the doses. The established approach of transforming 2D arrays of dose in a 3D one was satisfactory, validating it. The developed method showed to be an excellent alternative to quality control in radiosurgery using the radiochromic film to assess the absolute dose.
\end{abstract}

Keywords: Radiosurgery, acoustic neuroma, radiochromic film. 


\section{INTRODUCTION}

Acoustic neuroma or Vestibular schwannoma arises from Schwann cells of the vestibulocochlear nerve (cranial nerve VIII). Most vestibular schwannoma have an intracanalicular component, with widening of the porus acousticus, which is present in $90 \%$ of cases. As these tumours enlarge, extracanalicular extension occurs. The diagnosis of vestibular schwannoma is made radiographically using contrast enhanced magnetic resonance imaging (MRI). Management options for newly diagnosed vestibular schwannoma include observation, surgery or radiation [1].

Tsao et al (2017) provided a summary on the published literature pertaining to acoustic neuroma management. A total of 405 articles were identified through Medline [1].

Observation is a controversial option. However, the risk-to-benefit ratio for observation versus intervention may favour a strategy of observation for these benign tumours especially if the acoustic neuroma does not grow significantly to negatively affect quality of life, or hearing, during a patient's remaining lifespan [1].

Surgery for acoustic neuroma carries a risk of complications. Some are specific to neurosurgery in this area of the brain, and include hydrocephalus, cerebrospinal fluid leak, facial nerve paralysis, facial numbness, hearing loss, ataxia, dysphagia, and major stroke. Even in the hands of very experienced acoustic surgeons, these risks cannot be eliminated. Radiosurgery provides an outpatient, noninvasive alternative for the treatment of small acoustic neuroma [2,3]

Advances in the technology have enabled the emergence of new radiotherapy modalities, improving the treatment of complex regions. Among the various types of radiotherapy modalities, the Stereotactic Radiosurgery (SRS) is a non invasive technique where a unique fraction of external radiation dose is delivered, with high precision to well-localized targets, within clearly defined limits, usually intracranial. The central feature of this technique is the high dose gradient for beyond the tumor's boundaries. In other words, the tumor receives high recommended doses and healthy tissues around it receive lower doses than the typical dose values delivered with conventional external beam radiotherapy (EBRT) [4,5]. The number of patients treated with SRS has increased in the last years due to the conservative nature of the treatment, the identical or better results than those achieved with surgery, low therapeutic morbidity and low cost. This technique has been used 
in the treatment of malign and benign tumors in adults, but has also become frequent for treatments of arteriovenous malformation of children [6].

SRS using linear accelerator has been validated in the literature [7-9]. Most recently, through a systematic series of quantitative commissioning experiments and end-to-end tests and their initial clinical experience, Kim et al (2012) demonstrated that the Novalis linear accelerator is a robust system, with the image guidance and MLC requirements to treat a wide variety of sites, in particular for highly accurate delivery of SRS and SBRT-based treatments [7].

As SRS deals with extremely sensitive regions and requires high accuracy with both radiation dose delivered to target volume and target volume localization, its quality control have to be rigorous [4].

The quality of a treatment is a result from several aspects, which can be classified as mechanical errors, location designated by image, dose planning, patient position, irradiation and others. To evaluate a radiosurgery treatment, is necessary to take into account all the factors involved in the treatment, in a combined way. The treatment cannot be considered of good quality if any of these aspects do not meet the recommended quality control standards [10].

Several publications [11-16] discussed the quality control of different SRS techniques and, most of them, are related to the systems Cyberknife and Gamma Knife. As the small fields used in SRS are characterized by high dose gradients, a lack of lateral particle equilibrium and a variation of energy spectra with beam sizes, a dosimeter with high resolution, tissue-equivalence and high precision is required [11]. Radiochromic film has several advantageous characteristics which make it an attractive dosimeter for many clinical tasks in radiation oncology [12]. Its potential has been demonstrated in several studies in the literature [11-15].

Garcia-Garduño and collaborators [13] measured transmission, scattered and penumbra radiation of a beam from a micro-multileaf collimation system integrated to a $6 \mathrm{MV}$ linear accelerator, making use of EBT radiochromic films. The results were compared with previous literature data obtained with different types of detectors. Results were in agreement with those reported in the literature, showing that basic dosimetric properties of a micro-multileaf for stereotactic radiosurgery and radiotherapy applications can be measured with high precision using EBT radiochromic films. 
Moutsatsos et al [14] highlighted the importance of the experimental verification of dose distribution in SRS treatments using a Gamma Knife for clinical practice. Relative dosimetry results achieved by VIP gel dosimeter and EBT radiochromic films were compared with the TPS calculation, for 4 and $18 \mathrm{~mm}$ collimators. It was concluded that only the gel dosimeter would be necessary to verify $3 \mathrm{D}$ dose.

Brezovich et al [15] measured dosimetric and spatial accuracy of stereotactic radiosurgery (SRS) delivered to targets as small as the trigeminal nerve (TN) using a standard external beam treatment planning system (TPS) and multileaf collimator-(MLC) equipped linear accelerator without cones or other special attachments or modifications. They concluded that Stereotactic radiosurgery (SRS) can be planned and delivered on a standard linac without cones or other modifications with better than $0.5 \mathrm{~mm}$ spatial and 5\% dosimetric accuracy.

Few studies make use of anthropomorphic phantoms in their evaluations, hampering the implementation of the obtained results to clinical situations [16-18].

Cheng et al [16] evaluated the CyberKnife radiosurgical system (Accuray, Inc., Sunnyvale, CA) total system studied for clinically relevant accuracy when targeting paraspinal lesions using impanted stainless steel fiducials. They demonstrated that CybeKnife system is capable os submilimeter accuracy.

Dellios et al [17] aimed to promote target localization accuracy in cranial stereotactic radiosurgery (SRS) applications by focusing on the correction of sequence-dependent (also patient induced) magnetic resonance (MR) distortions at the lesion locations. Results showed, in cranial SRS applications, thar the patient-specific distortion correction at the target location(s) is feasible and effective, despite the expense of longer imaging time since additional MRI scan(s) need to be performed. A phantom-based QA methodology was developed and presented to reassure efficient implementation of correction techniques for sequence-dependent spatial distortion.

Wiant et al [18] compared a Surface Imaging System vs a commercial room mounted x-ray localization system in a anthropomorphic head phantom with fiducial markers for SRS. X-Ray imaging and Surface Imaging (SI) showed similar accuracy over measurements at 72 different phantom positions. SI showed minimal performance loss with camera pods blocked. SI is a feasible option for intra-fraction radiosurgery localization based on these phantom measurements. 
None of the studies found in the literature evaluated the treatment verification by comparing the dose distribution obtained through experimental data and Treatment Planning System for SRS of acoustic neuroma.

The aim of this study was to evaluate the dose distribution in an antropomorphical phantom for a typical acoustic neuroma, located deeply inside the skull and close to the vital area of the brain, treated by SRS. An antropomorphic Alderson Rando phantom modified was used to evaluate the dose in the tumor region and brainstem, important organ of risk in an irradiation of an acoustic neuroma, using radiochromic film. Experimental results were compared with those provided by the BrainLAB iPLan RT Dose. An alternative approach of transforming 2D arrays of dose in a 3D one was proposed to be used for quality control in radiosurgery using the radiochromic film to assess the absolute dose.

\section{MATERIALS AND METHODS}

A Novalis Robotics linear accelerator with a 6 MV beam (Shaped Beam Surgery) was used to perform the stereotactic irradiation. A stereotactic kit was integrated to the accelerator, including the fixation mask, frameless base, stereotactic coordinate localization system, localization system by infrared reflection and multileaf collimators (MLC). In order to obtain the experimental dose distribution, an Alderson Rando phantom was used. One slice of Alderson's head was replaced by a water equivalent material (CNMC Company), manufactured with a compartment that would be used to simulate the tumor or accommodate radiochromic films. The manufactured slice has the same dimensions as the replaced one.

Materials simulating the auditory nerve tumor (cylinder of $1 \mathrm{~cm}$ diameter) and the brainstem (semicircle of $3 \mathrm{~cm}$ diameter) were manufactured in PVC (Figure 1) [18] to allow the localization of both structures inside the modified slice in a TC image. 


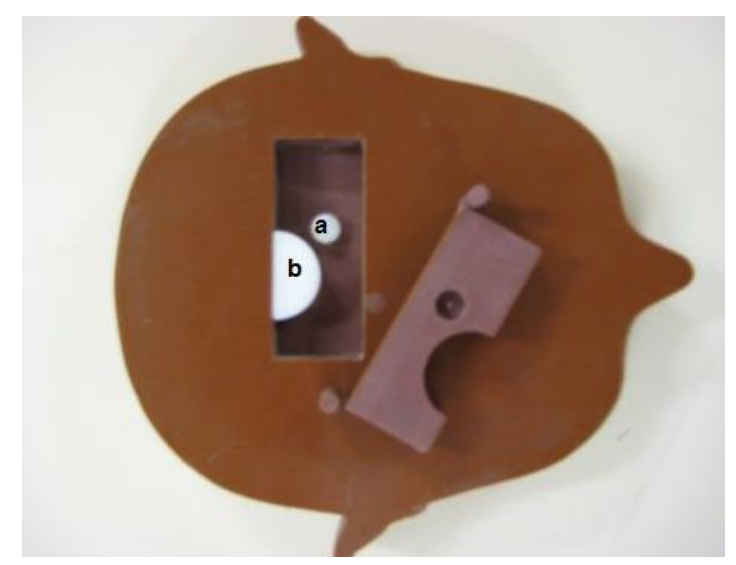

Figure 1: Alderson Rando phantom's replaced slice manufactured with simulation structures: a) tumor and b) brainstem, made in polyethylene.

The Alderson's head was fixed to the mask, stereotactic coordinate's localization system and frameless holder (figure 2) to be scanned in a Philips Bigbore Oncology tomograph. The CT image was afterward used to plan the treatment. Images were obtained with $0.1 \mathrm{~cm}$ thickness transverse sections, pitch of 1.0 and reconstructed with $36 \times 36 \mathrm{~cm}^{2}$ area, in order to cover all the stereotactic coordinate localization system volume.
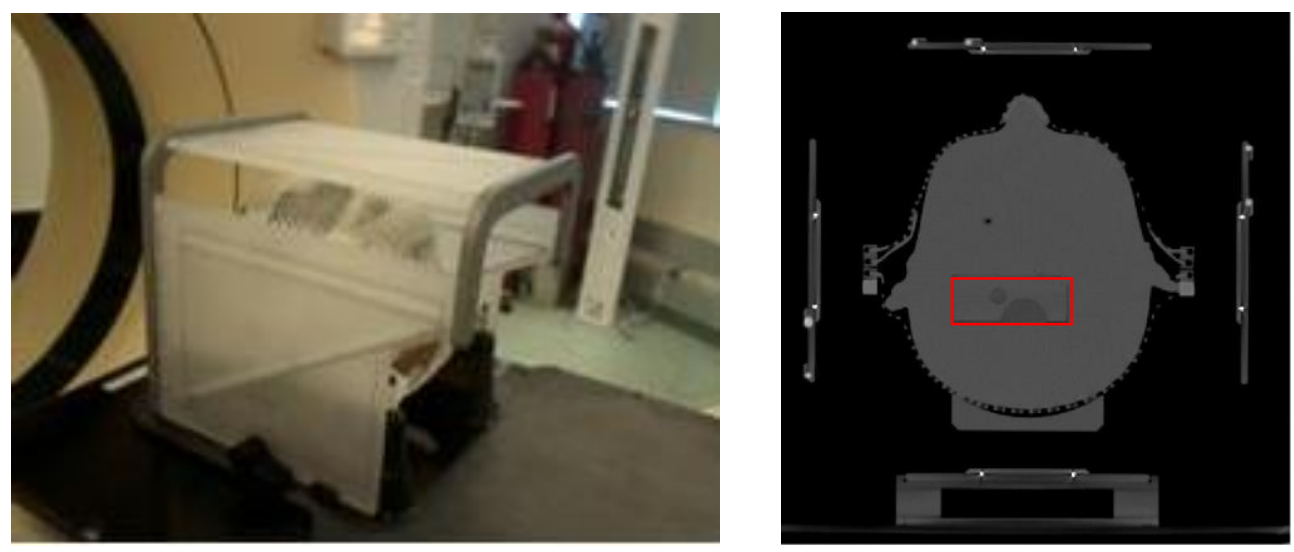

Figure 2: a) Alderson Random phantom's head fixed to the mask, stereotactic coordinate localization system and frameless holder at the tomograph; b) Transverse view of Alderson's head CT. Tumor and brainstem are highlighted in the red rectangle. Circle is the tumor and semicircle is the brainstem. 
Images were transferred to the BrainLAB iPLan RT Dose version 4.1.2 system. The treatment used a rectangular field with $2.2 \times 2.8 \mathrm{~cm}^{2}$, compatible with size and shape of the tumor, and prescription dose of 4.0 Gy at the planned target volume (PTV). The multileaf collimators (m3mMLC) using static shaped fields coupled to the Novalis Robotics linear accelerator were used. The calculation grid size of $1 \times 1 \times 1 \mathrm{~mm}^{3}$ was used by Brainlab iPlan. The dose value used was chosen based on the limits of radiochromic film detection and close to the typical dose values used in SRS treatments. Due to the requirement of high precision on dose deposition in SRS treatments, beyond evaluate the mechanical precision and isocenter stability, is important to check the positioning of the phantom before the beginning of the treatment. The stereotactic box was used to set the isocenter used in the treatment and, according to this box, the association between the coordinates and localization system by infrared reflection was done. Coordinates were confirmed by performing two X-Ray images, allowing the comparison between the tomography and the phantom position at the moment of the treatment.

The regions that simulate the PTV and the brainstem were removed and radiochromic films were positioned, oriented along the coronal plane, to be irradiated according to what was planned with the treatment planning system.

Gafchromic EBT 2 film from International Specialty Products, lot A11051003, were used to perform measurements [19-21]. In this film, active part of the films was reduced to a single layer 28 $\mu \mathrm{m}$ thick and a thin topcoat applied to a $175 \mu \mathrm{m}$ polyester substrate. Moreover, the coated layers are over-laminated with polyester. According to manufacturer, some of its main advantages include a higher tolerance to visible/ultraviolet light exposure and it can correct non-uniformity of the active layer thickness using a yellow marker dye [19]. EBT2 films have a weak energy dependence. The energy dependence of EBT2 was found to be relatively small within measurement uncertainties $(1 \sigma= \pm 4.5 \%)$ for all energies and modalities [20].

Films were cut into $3 \mathrm{~cm} \times 3 \mathrm{~cm}$ pieces and scanned with an Epson - Perfection V750 scanner. Sweeps were done in the transmission mode, with 300dpi and 48 bits RGB, without any color corrections.

In order to obtain the calibration curve, 13 pieces of the EBT film with $3 \times 3 \mathrm{~cm}^{2}$ were irradiated inside an Iba Dosimetry plastic phantom, model SP-34, with $1.045 \mathrm{~g} / \mathrm{cm}^{3}$, in the Novalis 
Robotics linear accelerator with a $6 \mathrm{MV}$ beam, $10 \times 10 \mathrm{~cm}^{2}$ field size and Monitor Units (MU) selected between 0 and 705 (table 1).

Table 1: Relation between MU and film identification number (85,08 cGy/100MU).

\begin{tabular}{cc}
\hline Identification of films & MU \\
\hline 1 & 0 \\
2 & 59 \\
3 & 118 \\
4 & 177 \\
5 & 235 \\
6 & 294 \\
7 & 353 \\
8 & 412 \\
9 & 447 \\
10 & 470 \\
11 & 494 \\
12 & 588 \\
13 & 705 \\
\hline
\end{tabular}

The plastic phantom was positioned at a source to surface distance (SSD) of $100 \mathrm{~cm}$, and each film piece was placed in the center of irradiation field at $5 \mathrm{~cm}$ deep, as can be seen at the Figure 3.

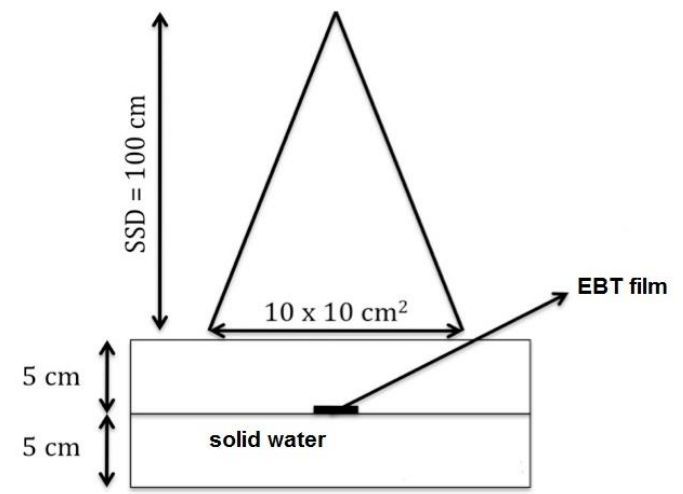

Figure 3: Set-up used to calibrate the radiochromic films. 
Each piece of the film was numbered and positioned, having as reference the PTV center, and being interspersed with acrylic plates of $0.1 \mathrm{~cm}$.

After the execution of all previously described stages, the phantom with the region to be treated replaced by radiochromic films was positioned in the linear accelerator Novalis Robotics and was irradiated following the same procedures planned by the software described previously in the TPS calculation.

The software ImageJ [22] and a homemade computational code [23] were used to perform the radiochromic film image analysis and to construct a Dose Volume Histogram (DVH), respectively.

All calibration films were scanned within at least $24 \mathrm{~h}$ after exposure, in order to avoid major post exposure optical density changes. As the scan response of EBT2 radiochromic is sensitive to the orientation of the film on the scanner, the orientation of the film in each image was recorded and kept the same on the scanner bed around the central region, in order to minimize the lateral displacement effect, as well as the uncertainty from scanner inhomogeneity.

The optical density was obtained using a color flatbed scanner for image digitization on red $(\mathrm{R})$, green $(\mathrm{G})$ and blue (B) bands of the visible spectrum. Since the dose cannot depend on the color channel X selected for evaluation, the triple-channel approach uses the information of a sequence of multiple channels in a least squares error function of differences between three channels. This minimization problem allows the separation of dose information and thickness or even artifact that disturbs each dose value. This approach is a smart use of parametric regression models in minimization problems [23].

If the error term is normally distributed, then the least squares estimator is a Maximum Likelihood Estimator (MLE). The triple-channel dose optimization procedure reduces the dose difference resulting from all channels by varying a single parameter that results in a disturbance map. These results allow film uniformity corrections in optical density values from all color channels. The method used calculates three dose values for each pixel, presented as a three color dose image. Existing dose discrepancies between dose values resulting from the three color channels are presented in the consistency map, which is represented by the average dose values from red, green and blue channels [23]. 
Regions of interest (ROI) were used to define the mean channel pixel value from each irradiated piece. Afterwards calibration curves from all channels were estimated using the 'calibration kernel' Gafgui [24] and these same ROI were used to calculate dose values using both triple-channel method, optimization via Nonlinear Least-Absolute Deviations and least-median-ofsquares robust optimization. When the robust method proposed is applied, the difference from blue and red channel doses was found to be very small, around $0.0001 \%$. It implies that both marker dye blue channel correction for non-uniformities and dosimetric results may have their best performance [23].

The ROI set was done by a hypothetical reconstruction of an interception between a plane and a cylinder, considering that the boundary conditions and the trapping area within the interception represent the exact size of the ROI. The ROI's length calculation was obtained from the central plan area of the cylinder. The first film was positioned on the central axis of the cylinder and the following films were placed interspersed with acrylic plates. Knowing the position of the film in the $\mathrm{z}$ axis the length $\mathrm{L}$ of the ROI could be determinated on the $\mathrm{x}$ axis, using the equation 1 , as can be seen in the figure 4 , where $\mathrm{R}$ is the cylinder ratio, $\mathrm{k}$ the position of each film in the $\mathrm{z}$ axis and $\mathrm{L}$ is the ROI's length in the $\mathrm{x}$ axis. All measurements were performed using a digital paquimeter. Statistical uncertainties are less than $0.5 \%$ over a given ROI.

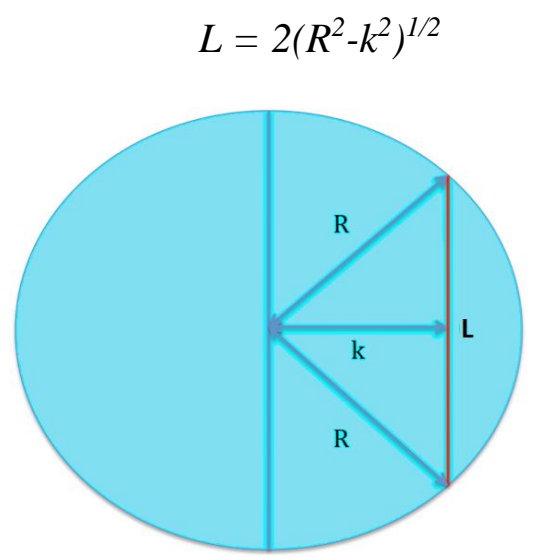

Figure 4: Illustration for ROI's width calculation on x axis, generated through interception between a plane and a cylinder. 


\section{RESULTS AND DISCUSSION}

The statistical evaluation of the dose was obtained from the DVH generated by TPS (Figure 5), allowing to obtain the maximum dose and the percent volume of irradiated PTV, supporting the choice of a proper planning.

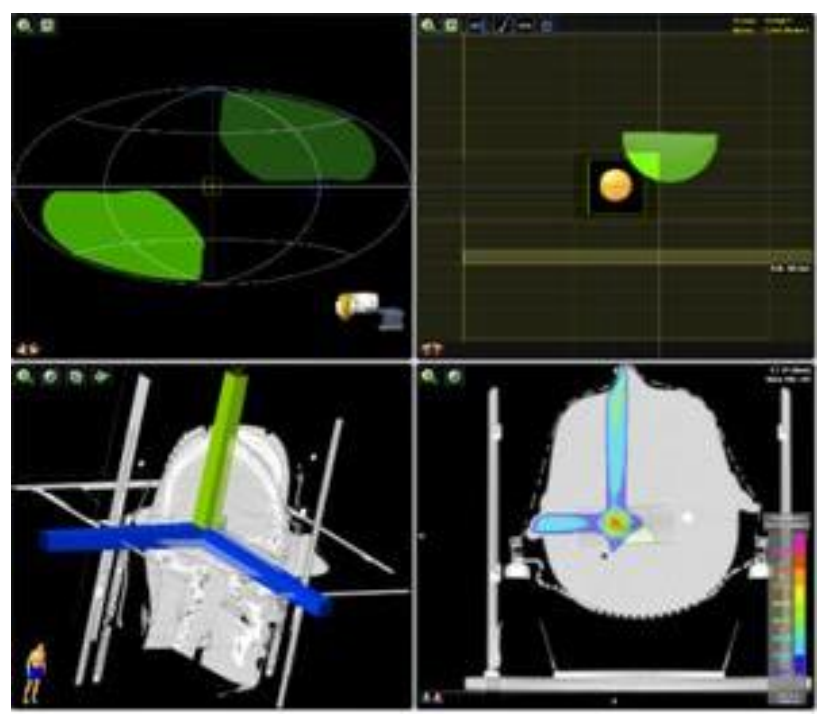

Figure 5: Screens of BrainLAB iPLan RT Dose version 4.1.2 system. In the upper right part are shown the structures (PTV in orange and the brain stem in green) drawn in the TPS. In the lower left part, the three fields planned for the delivery of the dose are illustrated. And in the lower right, the axial image, illustrating the dose distribution in the PTV.

The DVH shows that $94 \%$ of the PTV volume received $94 \%$ of the prescribed dose, and the maximum dose of 4.04 Gy was delivered to $1 \%$ of total volume.

The settings determined by TPS were transferred to the accelerator, so that the treatment could be performed. The settings used by the accelerator are shown in table 2 . 
Table 2: Settings used by the accelerator.

\begin{tabular}{cccccccc}
\hline Beam & $\begin{array}{c}\text { Couch } \\
\text { angle }\left({ }^{\circ}\right)\end{array}$ & $\begin{array}{c}\text { Gantry } \\
\text { angle }\left({ }^{\circ}\right)\end{array}$ & $\begin{array}{c}\text { Equivalent } \\
\text { Depth (mm) }\end{array}$ & $\begin{array}{c}\text { SSD } \\
(\mathbf{m m})\end{array}$ & $\begin{array}{c}\text { Isocenter } \\
\text { Dose (Gy) }\end{array}$ & $\begin{array}{c}\text { Beam } \\
\text { weight } \\
(\mathbf{\% )}\end{array}$ & MU \\
\hline 1 & 0 & 0 & 123.3 & 877.0 & 1.33 & 33.3 & 227 \\
2 & 0 & 270 & 69.9 & 930.4 & 1.34 & 33.3 & 175 \\
3 & 270 & 270 & 108.7 & 897.1 & 1.33 & 33.3 & 212 \\
\hline
\end{tabular}

EBT Gafchromic films were placed on the water equivalent slab and three measurements were performed, in order to obtain its average position. Through the location of each film it was possible to set the dimensions of each ROI, as can be seen in table $3 . \bar{Z}_{\text {Theoretical }}$ is the position of the film on the $\mathrm{Z}$ axis of the tumor center in relation to the reference point, the same reference point that was used to determine the position of each radiochromic film.

Table 3: ROI's length of each film positioned in PTV region.

\begin{tabular}{|c|c|c|c|c|}
\hline Film & $\begin{array}{c}\mathbf{K} \\
=\left|\bar{Z}-\bar{Z}_{\text {Theoretical }}\right| \\
(\mathbf{m m})\end{array}$ & $\begin{array}{c}\mathbf{K}^{2} \\
=\left|\bar{Z}-\bar{Z}_{\text {Theoreticad }}\right|^{2} \\
\left(\mathbf{m m}^{2}\right)\end{array}$ & $\mathbf{L}(\mathbf{m m})$ & $\mathbf{L}$ (pixel) \\
\hline 1 & 4.65 & 21.62 & 3.68 & 44 \\
\hline 2 & 3.12 & 9.73 & 7.81 & 93 \\
\hline 3 & 1.87 & 3.48 & 9.28 & 110 \\
\hline 4 & 0.59 & 0.34 & 9.93 & 118 \\
\hline 5 & 0.86 & 0.73 & 9.85 & 117 \\
\hline 6 & 2.41 & 5.81 & 8.76 & 104 \\
\hline 7 & 3.89 & 15.11 & 6.29 & 75 \\
\hline
\end{tabular}


The Figure 6 shows one of the calibration curves obtained using a least squares polynomial fitting without background compensation. Multichannel dosimetry does not require the use of nonirradiated film for the collection of optical density deduced from the background [24].

Optical density was plotted versus absorbed dose, where experimental data are represented by dots and the dashed line represents the calculated curve. From the curve is possible to obtain an equation to represent the experimental data with an uncertainty of $4.5 \mathrm{cGy}$.

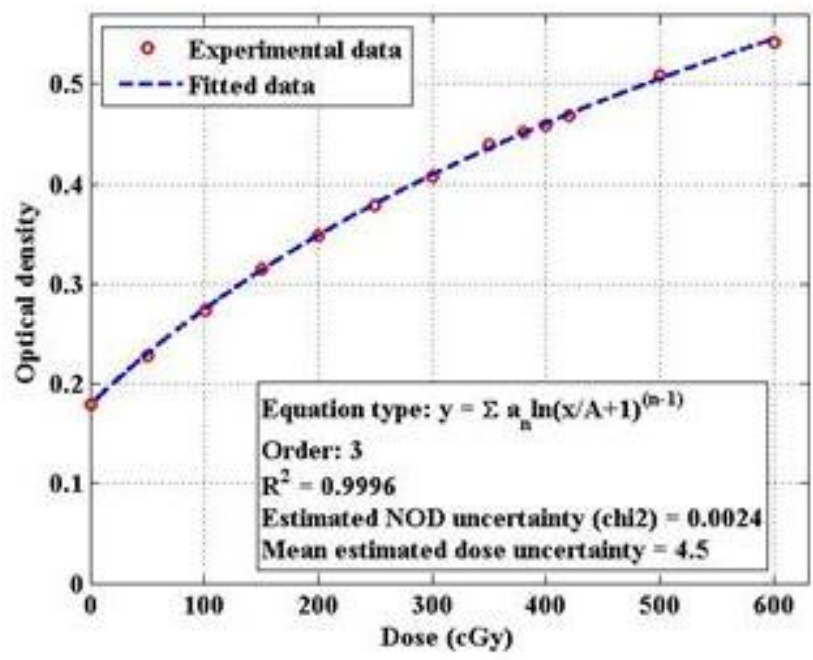

Figure 6: Graph illustrating the calibration curve obtained for Gafchromic EBT 2 film, scanned in an Epson Perfection V750 PRO scanner.

Figure 7 shows the DVH comparison between the radiochromic film measurements and the TPS calculation for the tumor. 


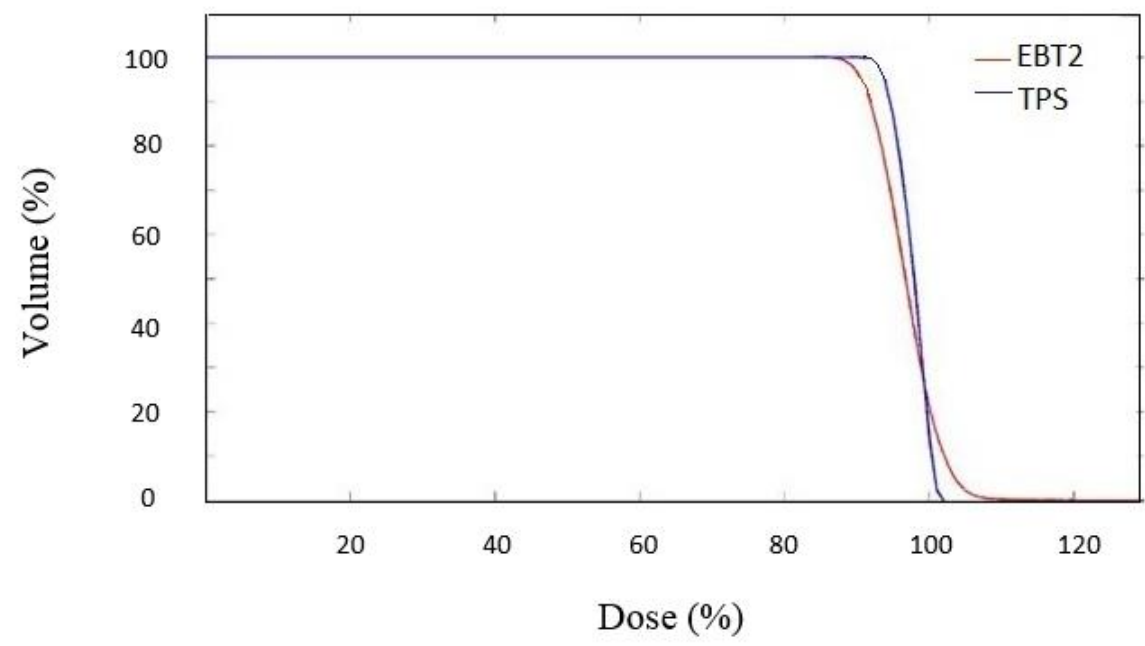

Figure 7: Experimetal DVH obtained with Gafchromic EBT 2 film (red line) and calculated DVH generated by TPS (blue line) for the PTV.

The DVH generated by TPS shows that $94 \%$ of the PTV volume received $94 \%$ of the prescribed dose, and the maximum dose of 4.04 Gy was delivered to $1 \%$ of total volume. Comparing this result with the experimental DVH, it is observed that experimental results present a loss of $3.2 \%$ of the prescribed dose for the same amount of irradiated volume, showing an acceptable agreement with the planning results.

Figure 8 shows the DVH comparison between the radiochromic film measurements and the TPS calculation for the brainstem, the most important organ of risk in an irradiation of an acoustic neuroma. 
a)

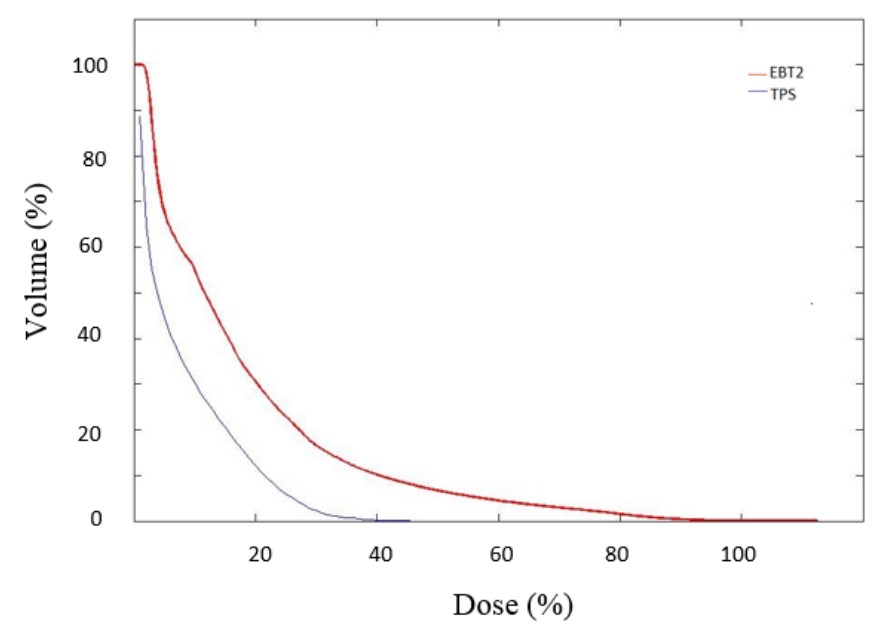

b)

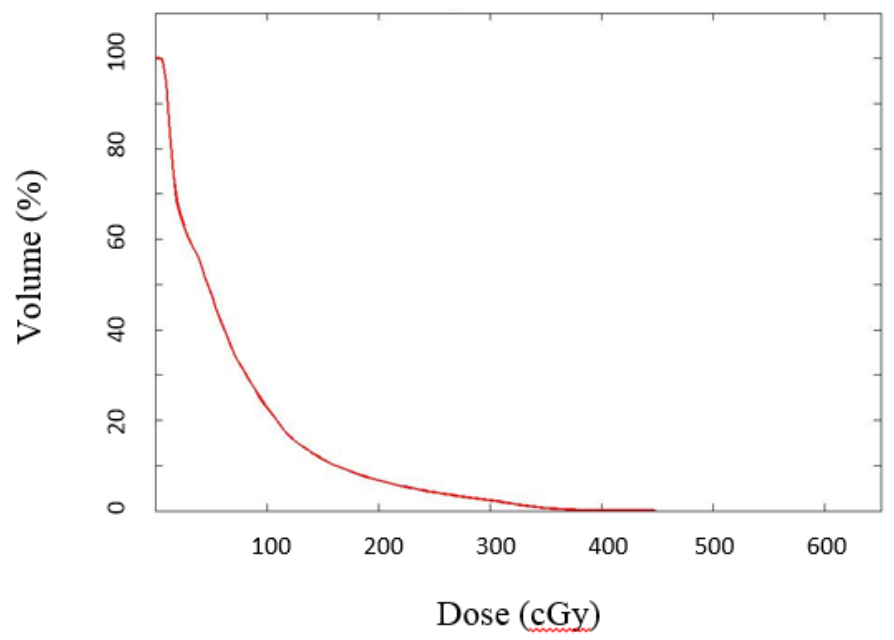

Figure 8: a) Experimetal DVH obtained with Gafchromic EBT 2 film (red line) and calculated DVH generated by TPS (blue line) for the brainstem; b) Experimetal DVH obtained with Gafchromic EBT 2 film (red line) with dose in cGy.

For the brainstem, we observe an underestimation of the dose by TPS (figure 8a). In the simulation, due to the limitation of the radiochromic film, a dose of 4 Gy to the tumor was prescribed and a maximum dose in the brainstem was measured between 4 to 4.5 Gy as shown in 
the figure $8 \mathrm{~b}$. Extrapolating a prescription of $12 \mathrm{~Gy}$, it would reach a maximum dose between 12 and $13.5 \mathrm{~Gy}$ in the brainstem. For single fraction SRS, maximum brainstem dose of 12.5 Gy is associated with low $(<5 \%)$ risk. Higher doses (15- 20 Gy) have been used with low reported incidence of complication in patient groups with poor prognosis for long-term survival [25].

Despite the agreement between the TPS histograms and the experimental one, the experimental DVH has a greater dispersion. The spacing of the film planes, shown in the table 3 , could influence this difference in dispersions.

Results showed that the developed method of transforming 2D arrays of dose in a 3D one is satisfactory, validating it.

\section{CONCLUSION}

The proposal of this paper was to assess the dose distribution in a SRS treatment of an acoustic neuroma from the treatment planning system and through dosimetric evaluations using Gafchromic EBT 2 film and a modified Alderson Rando phantom head. To achieve this goal, the head of the anthropomorphic phantom Alderson Rando was modified, replacing a phantom slice by a water equivalent slab containing an object simulating the tumor. It was also able to accommodate some radiochromic films. As radiochromic films provide two-dimensional dose maps, the challenge was to develop a methodology which allows the reconstruction of a tridimensional (3D) matrix from a two-dimensional dose map, in order to obtain a Dose Volume Histogram. An agreement around 3\% between experimental data and TPS's calculations for the tumor was found, showing an acceptable concordance with the planning results. For brainstem, TPS underestimated the dose. The extrapolated maximum dose obtained is compatible with low risk to generate complication to the patients. As opposite to what Moutsatsos et al [14] asserts, not only gel dosimetry could offer 3D dose verification, but the developed method shows to be an excellent alternative to Quality control in radiosurgery. 


\section{ACKNOWLEDGMENT}

The authors acknowledge the Radiotherapy sector of Quinta D'Or Hospital for allowing access to the equipments and for the support during the performance of the experimental measurements. This work was supported by FAPERJ and CNPq.

\section{REFERENCES}

[1] TSAO, M.N.; SAHGAL, A.; DE SALLES, A.; HAYASHI, M.; LEVIVIER, M.; MA, L.; MARTINEZ, R.; RÉGIS, J.; RYU, S.; SLOTMAN, B.J.; PADDICK, I. Stereotactic radiosurgery for vestibular schwannoma: International Stereotactic Radiosurgery Society (ISRS) Practice Guideline. J. Radiosurg. SBRT, v. 5, p. 5-24, 2017.

[2] FRIEDMAN, W.; FOOTE, K.D. Linear accelerator-based radiosurgery for vestibular schwannoma. Neurosurg. Focus, v.14(5):e2, 2003.

[3] POWELl, C.; MiCAllEF, C.; GONSAlVES, A.; WHARRAM, B.; ASHLEY, S.; BRADA, M. Fractioned stereotactic radiotherapy in the treatment of vestibular schwannoma (acoustic neuroma): predicting the risk of hydrocephalus. Int. J. Radiation Oncology Biol. Phys., v.80, p. 11433-1150, 2011.

[4] LEKSELL L. Sterotactic method and radiosurgery of the brain. Acta Chir. Scand., v.102, p. 316-319, 1951.

[5] SPIEGELMANN, R.; LIDAR, Z.; GOFMAN, J., ALEZRA, D.; HADANI, M.; PFEFFER, R. Linear accelerator radiosurgery for vestibular schwannoma. Neurosurgery, v. 94, p:7-13, 2001.

[6] MASCARENHAS, F.; COSTA, M.; ORTIZ M.; ALMEIDA, A.; CARVALHO, H.; FERREIRA A.; CATTONI, M. Radiocirurgia Estereotáxica em Tumores Benignos e Malignos do Sistema Nervoso Central. Acta Med. Port., v. 18, p:45-60, 2005.

[7] KIM, J.; WEN, N.; JIN, J-Y.; WALLS, N.; KIM, S.; LI, H.; REN, L.; et al. J Appl. Clin. Med. Phys., V. 13, P: 124-151, 2012. 
[8] LUTZ, W.; WINSTON K.R.; MALEKI, N. A system for stereotactic radiosurgery with a linear accelerator. Int. J. Radiation Oncology Biol. Phys., V. 14, p: 373:81, 1988.

[9] VERELlEN, D.; LINTHOUT, N.; BEL, A.; DEN BERGE, D.V.; D’HAENS, J.; STORME, G. Assessment of the uncertainties in dose delivery of a commercial system for linac-based stereotactic radiosurgery. Int. J. Radiat. Oncol. Biol. Phys., v. 44, p:421-433, 1999.

[10] TECDOC - Aspectos Físicos da Garantia da Qualidade em Radioterapia. Protocolo de Controle da Qualidade. TECDOC 151, Ministério da Saúde, INCa - Instituto Nacional de Câncer, Rio de Janeiro, RJ, Brasil, 2001.

[11] HUET, C.; DAGOIS, S.; DERREUMAUX, F.T.; CHENAF, C.; ROBBES. Characterization and optimization of EBT2 radiochromic films dosimetry system for precise measurements of output factors in small fields used in radiotherapy. Rad. Meas., v. 47, p: 40-49, 2012.

[12] HOWARD, M.E.; HERMAN, M.G. GRAMS, M.P. Methodology for radiochromic film analysis using FilmQA Pro and ImageJ. PLoS ONE, v. 15(5): e0233562.

[13] GARCIA-GARDUNO, O.A.; CELIS, M.A.; LÁRRAGA-GUTIÉRREZ, J.M.; MORENOJIMÉNEZ, S.; MATTINES-DÁVALOS, A.; RODRIGUEZ-VILLAFUERTE, M. Radiation transmission, leakage and beam penumbra measurements of micro-multileaf collimator using GafChromic EBT film. J. Appl. Clin. Med. Phys., v. 9, p.90-98, 2008.

[14] MOUTSATSOS, M.; PETROKOKKINOS, L.; ZOURARI, K.; PAPAGIANNIS, P. et al. Gamma Knife relative dosimetry using VIP polymer gel and EBT radiochromic films. Journal of Physics, v. 164, 012053, 2009.

[15] BREZOVICH, I.A.; WU, X.; POPPLE, R.A.; COVINGTON, E.; CARDAN, R.; et al. Stereotactic radiosurgery with MLC-defined arcs: Verification of dosimetry, spatial accuracy, and end-to-end tests. J. Appl. Clin. Med. Phys., v. 20, p: 84-98, 2019.

[16]CHENG, Y.; MAIN, W.; TAYLOR, M.S.; KUDUVALLI, G.; APUZZO, M. L. J. et al. An antropomorphic phantom study of the accuracy of CyberKnife spinal radiosurgery. Neurosurgery, v. 55, p: 1138-1149, 2004.

[17]DELliOS, D.; PAPPAS, E. P.; SEIMENIS, I.; PARASKEVOPOULOU, C.; LAMPROPOULOS, K.; et al. Evaluation of patient-specific MR distortion correction schemes for improved target localization accuracy in SRS. Med. Phys., v. 47, 2020. 
[18] WIANT, D.; LIU, H.; HAYES, L.T.; SHANG, Q.; MUTIC, S.; et al. Direct comparison between surface imaging and orthogonal radiographic imaging for SRS localization in phantom. J. Appl. Clin. Med. Phys., v. 20, p: 137-144, 2019.

[18] BOIA, L.S.; MENEZES, A.F.; CARDOSO, M. A. C.; DA ROSA, L. A. R.; BATISTA, D. V. S.; CARDOSO, S. C.; SILVA, A.X.; FACURE, A. Application of digital image processing for the generation of voxels phantoms for Monte Carlo simulation. App. Rad. Isotopes, v. 70, p : 144-148, 2012.

[19] SANTOS, T.; VENTURA, T.; LOPES, M. C. A review on radiochromic film dosimetry for dose verification in high energy photon beams. Rad. Phys. Chem., v. 179, 109217, 2021.

[20] ANDRÉS, C.; DEL CASTILlO, A.; TORTOSA, R.; ALONSO, D.; BARQUERO, R. A comprehensive study of the Gafchromic EBT2 radiochromic film. A comparison with EBT. Med. Phys., v. 37, p: 6271-6278, 2010.

[21] AEJOMANDY, B.; TAYLOR, R.; ANAND. A.; SAHOO, N.; GILLIN, M. et al. Energy dependence and dose response of Gafchromic EBT2 film over a wide range of photon, electron, and proton beam energies. Med. Phys., v. 37, p: 1942-1947, 2016.

[22] FERREIRA, T.; RASBAND, W. ImageJ User Guide, imagej.nih.gov/ij/docs/guide/userguide.pdf, 2014.

[23] AlVES, V. G. L.; CARDOSO, S.C.; DA SILVA, A. X. Gafchromic EBT2 dosimetry via robust optimization. Computer Physics Communications, v. 184, p: 1708-1716, 2013.

[24] BOUCHARD, H. ; LACROIX, F. ; BEAUDOIN, G. ; CARRIER, J.F. ; KAWRAKOW, I. On the characterization and uncertainty analysis of radiochromic film dosimetry. Med. Phys, v. 36, p: 1931-1946, 2009.

[25] MAYO, C.; YORKE, E.; MERCHANT, T. E. Radiation associated brainstem injury. Int. J. Radiation Oncology Biol. Phys., v. 76, p: S36-S41, 2010. 